\title{
دور القابلية للسير في تحقيق نظام نقل مستدام
} م/مي ياسر عبد الظاهر مفتاح معيدة بقسم عمارة-كلية الهندسة بالمطرية - جامعة حلوان - جمهورية مصر العربية

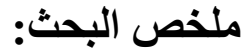

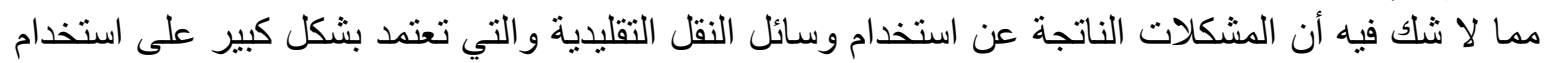

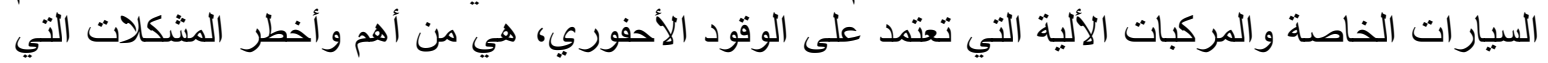

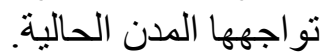

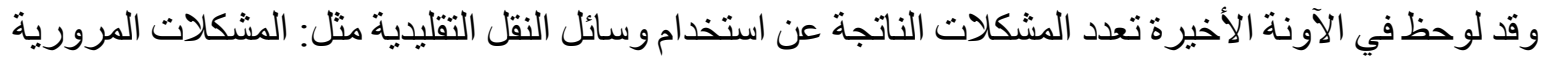

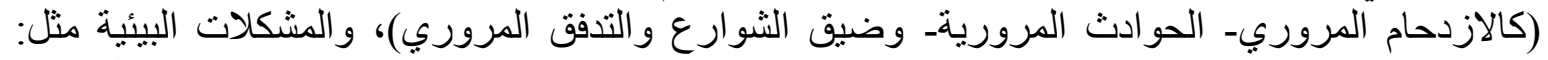

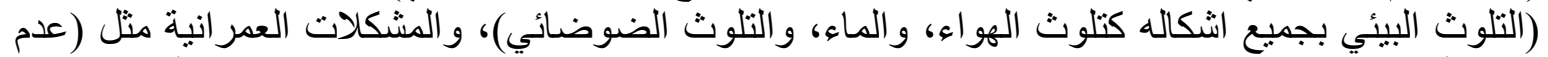

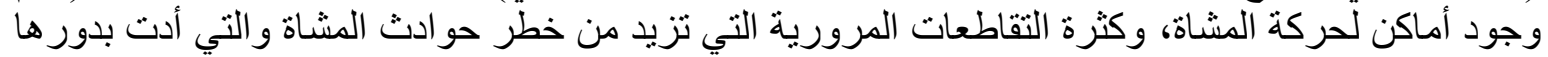

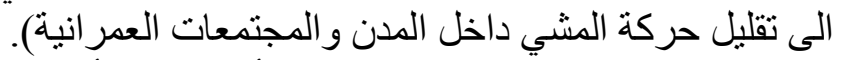

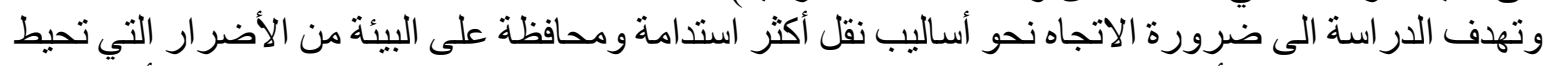

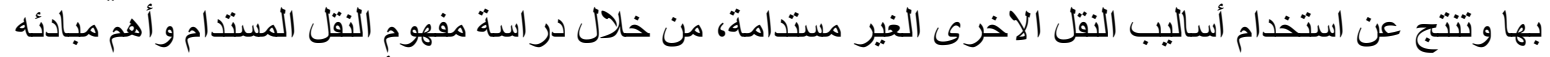

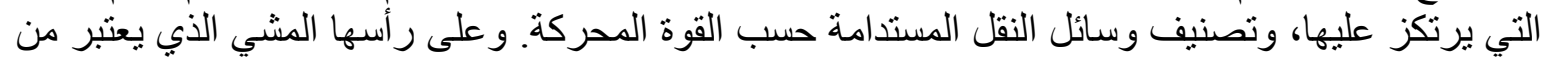

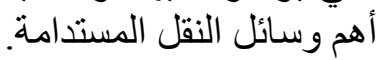
ويمكننا ان نستتج من خلال البحث أهم المعايير الأساسية الهامة لزيادة قابلية السير داخل الددن الحضرية

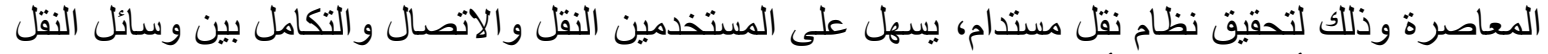
سواء كان ذلك للأجيال الحالية أو المستقلية.

مصطلحات البحث: النقل المستدامـ الاستدامة ـالسير - قابلية السير - النقل النشط.

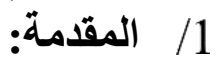

تعتبر قابلية السير Walkability من أهم المصطلحات التي يتم دراستها في نطاق واسع، حيث يعتبر السير

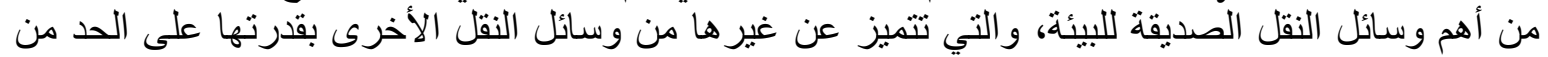

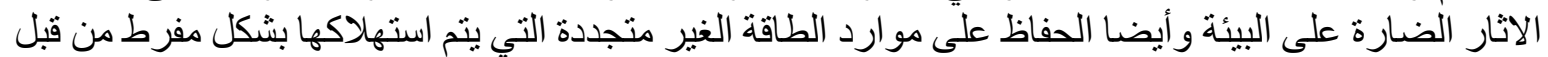
وسائل النقل التقليدية، ويعتبر المشي من أهم وسائل النقل المستدام من أنجح نظم النقل التي لها فو ائد اقتصادية و عمر انية وبئية النية.

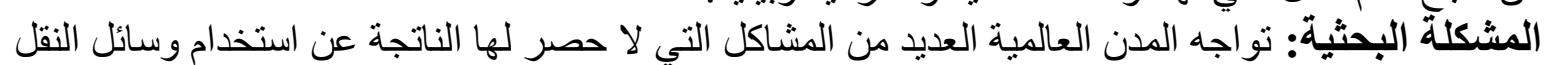

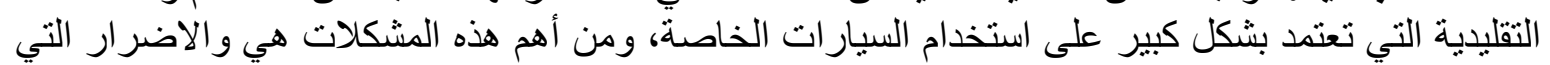

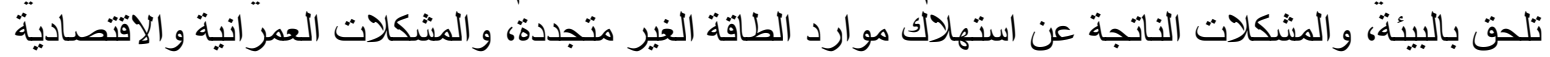

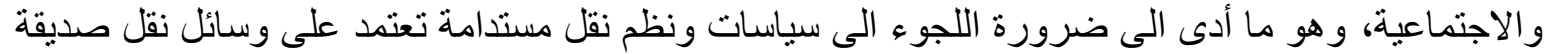

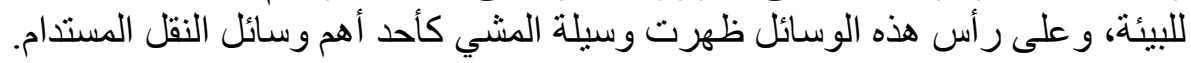

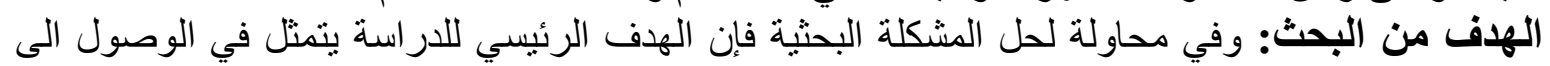

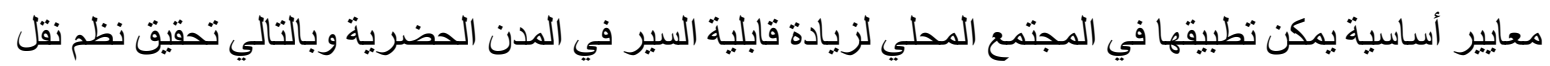

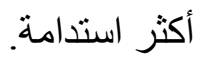


منهجية البحث: للوصول إلى الهدف الرئيسي للبحث فلابد من مرور الدراسة بعدة مناهج بحثية وهي: أو لاً:

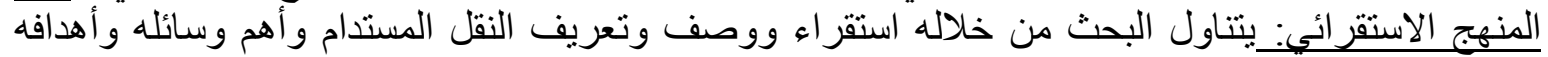

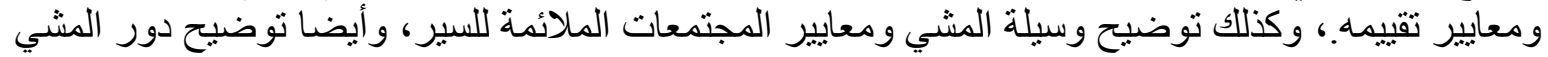
في تحقيق نظم نقل مستدامة. ثانيا: المنهج الوصفي التحليلي: يتمب من خلاله رصدي رصد وتحليل أحد التجارب العالمية التي تطبق المعايير الأساسية

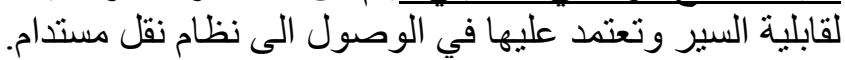
2/ مفهوم النقل المستثام

النقل المستدام هو مصطلح يعبر عن التنمية المستدامة داخل قطاع النقل، فهو مصطلح يجمع بئن مفين مفهومين

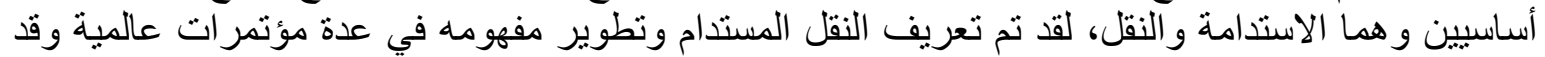

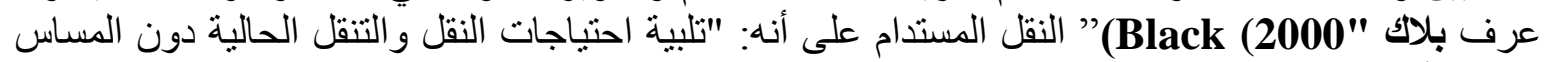

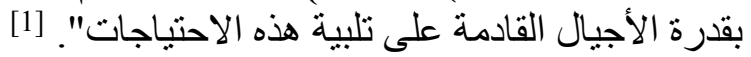

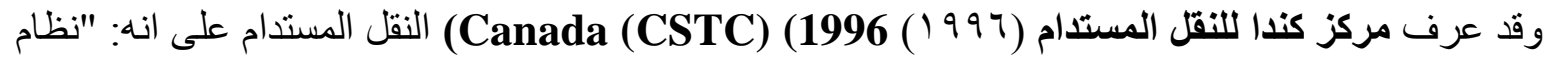

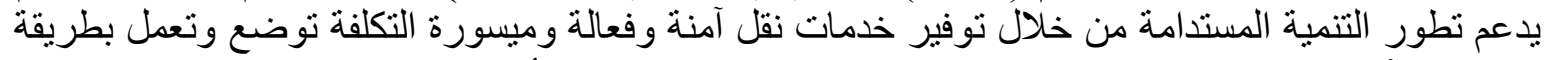

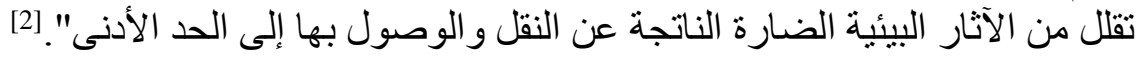

\section{3/ ت تاريخ النقل المستدام}

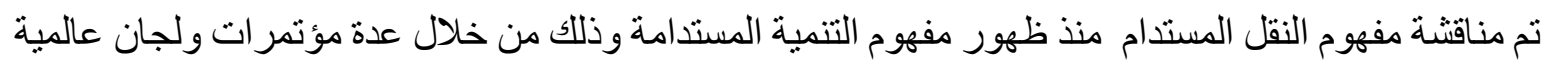

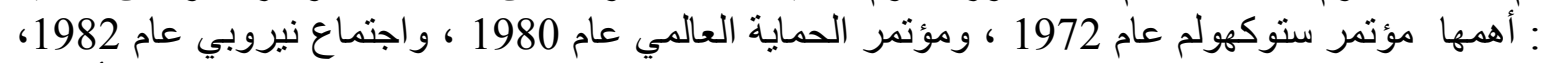
ولجنة مستقبلنا المشترك عام 1987وقمة ريو عام 1992، وصو لا الى خطط ما بعد 2015 التي وضعت ألى أهداف

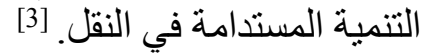
4/ مبادئ النقل المستدام

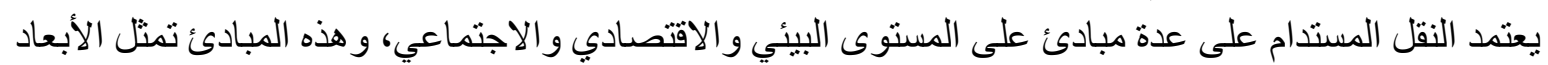
الثلاثة للاستدامة [4] كما هو موضي علدم في شكل (1) :

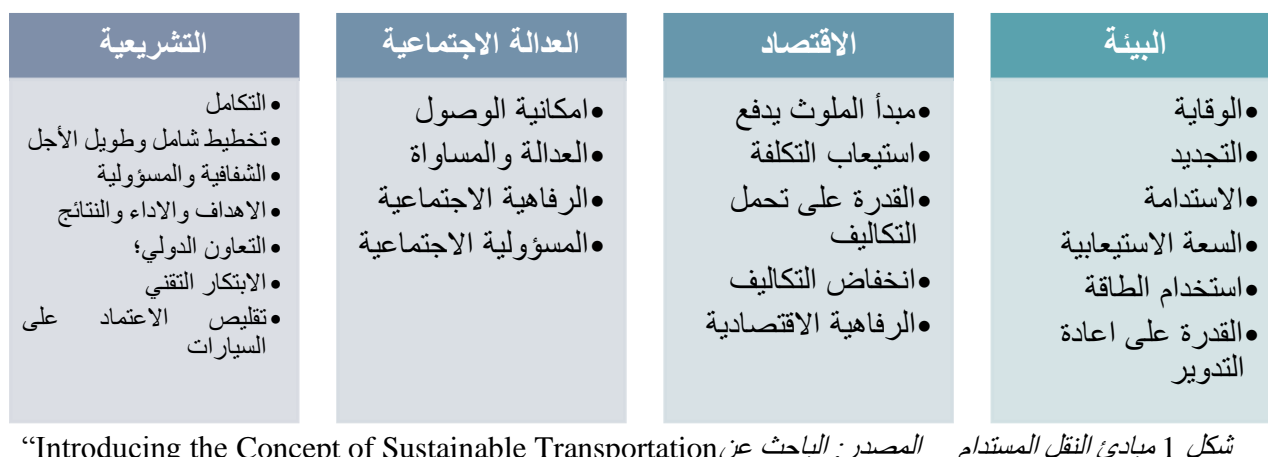

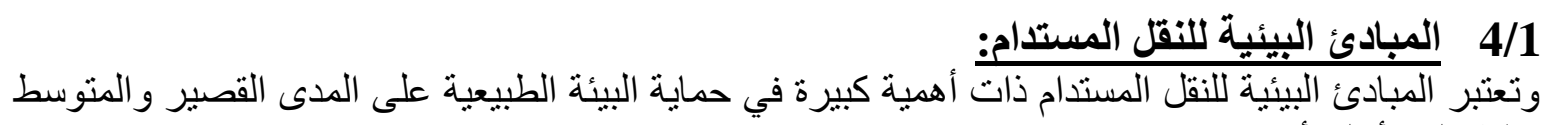

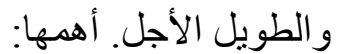
• الوقاية: الذي يهذف إلى منع التدهور البيئي و اتخاذ الإجر اءات الفعالة من حيث التكلفة لمنع أو التقليل

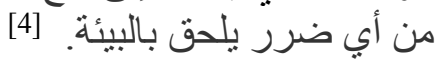

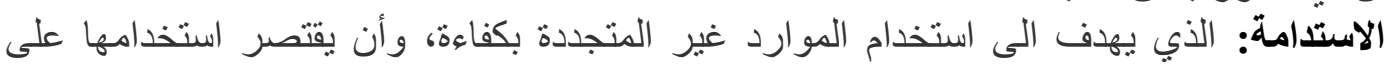
المستويات التي يمكن موازنتها بالموارد المتجددة. 
•القدرة على استيعاب التكلفة: ولكي تدعم الأسواق العالمية وسائل النقل المستدامة ينبخي أن تكون

الأسعار و التكاليف في حدود مقدرتهاب.

•انخفاض التكاليف: ينبغي للسياسات أن تهدف إلى الحد من تكاليف النقل. ويتطلب ذلك أن تكون تكاليف

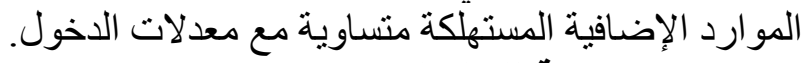

4/3

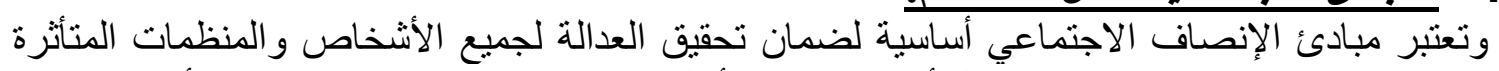

بالنقل. وتسعى المبادئ إلى تعزيز نظام نقل أكثر تنو عا من أجل إتاحة إمكانية وصول الإنية الناس الإنس إلى الأماكن و السلع

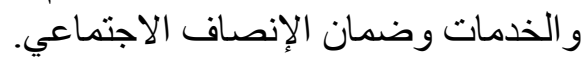

/5/ تصنيف وسائل النقل المستدام

تتقسم وسائل النقل المستدام حسب القوة المحركة إلى عدة أقسام انظر الرسم التوضيحي (1):

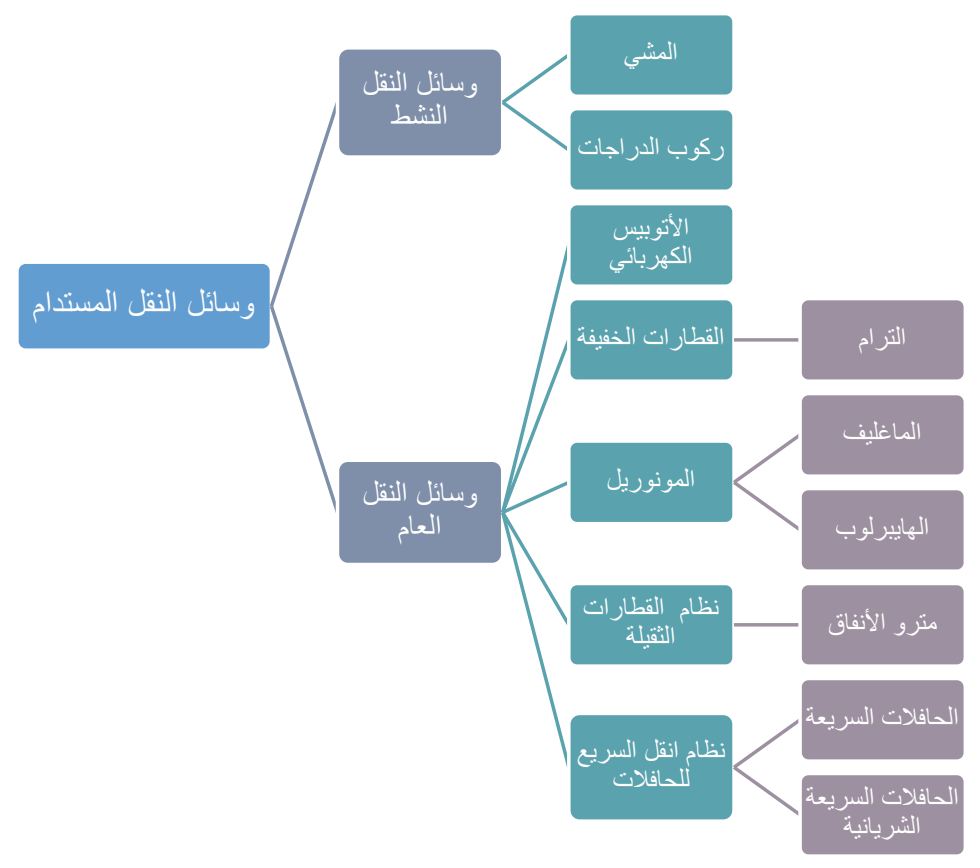

رسم توضيحي اتصنيف وسائل النقل المستدام المصدر: الباحث

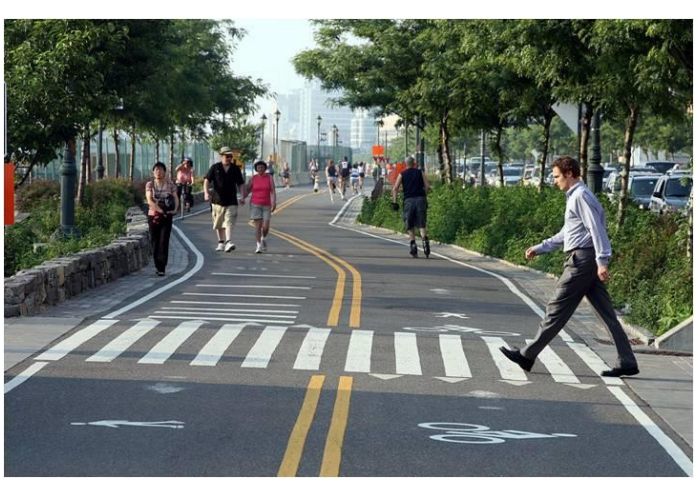

شكل 2/الهشي من أهم وسائل النقل النشط الهصدر: https://making-cities-safer.com/walkability-set-city-
وكما هو موضح في الرسم التوضيحي السابق فان المشي

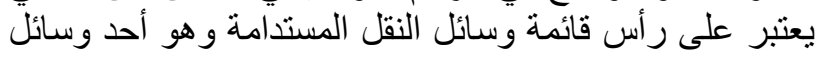

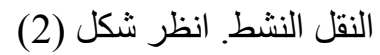
يعرف النقل النشط (النقل غير الآلي) على انهل: أسلوب

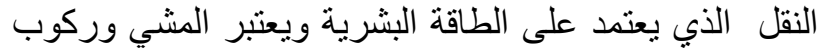

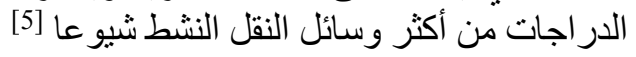

$$
\text { 6 / تعريف السير }
$$

يعرف السبرWalking في السياق الحضري: على أنه

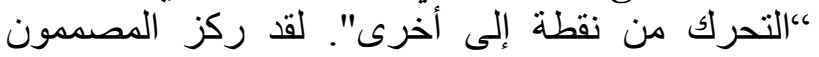
و المخططون الحضريون على هذا المصطلح مؤخرًا لتوفير 
بيئة مستدامة وزيادة القدرة على وصول الأفر اد إلى جميع الوجهات مثل أماكن العمل و الترفيه و التسوق بواسطة

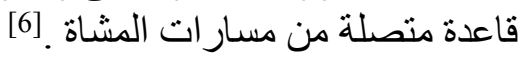

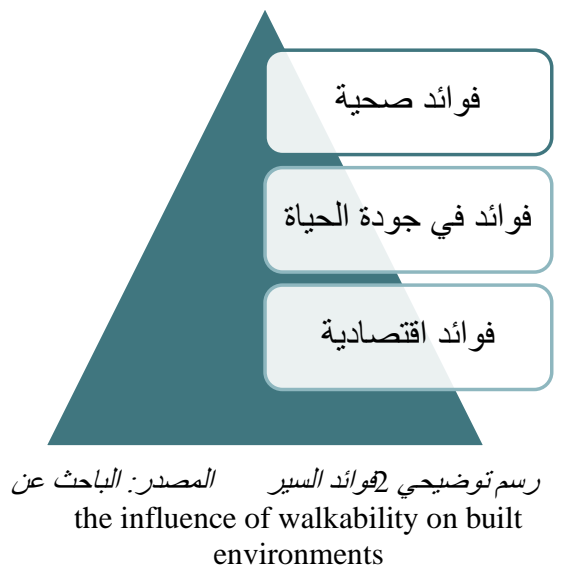

/7 فوائد السير

يعتبر السير Walking من أهم وسائل النقل المستدامة وأقلها

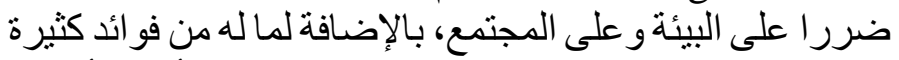

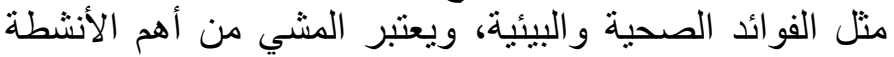
الترفيهية والاجتماعية انظر رسم توضيحي (2). تعتبر الفوائد الصحائد الصحية من أهم فوائد المشي على المجتمع ووفقا لمركز

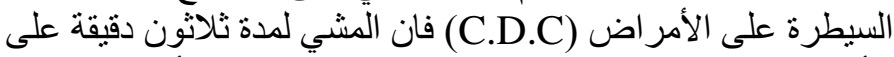

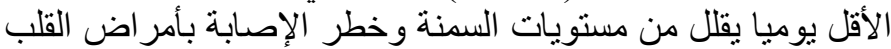
و الأو عية الدموية و السكر و غير ها من الأمر اض. لاض. environments

7/2

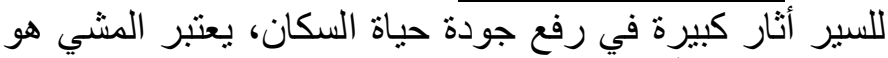

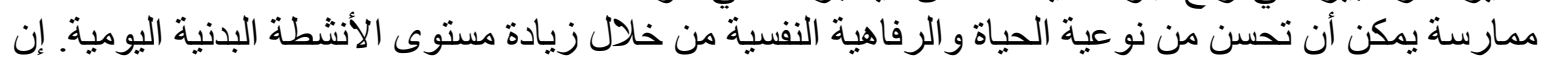

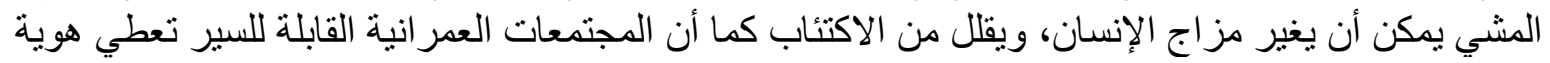
فريدة للبيئة المبنية وتزيد من شعور المو اطنين بالانتماء.

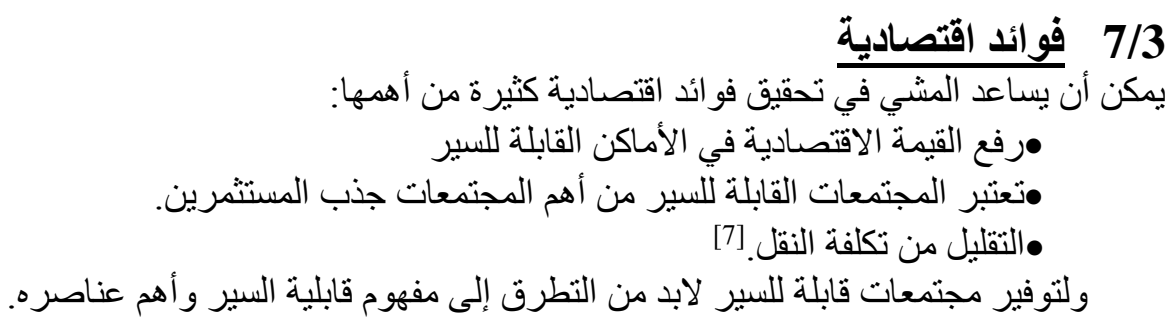

8

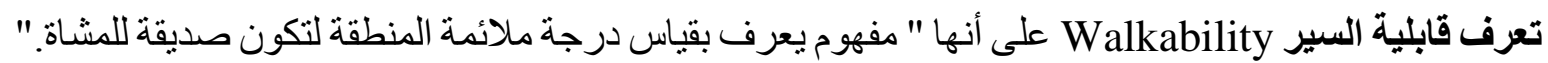
وقد اختلف تعاريف قابلية السير اعتمادا على قو اعد متنوعة فهنالك تعريف لساورث "Southworth "يبدو

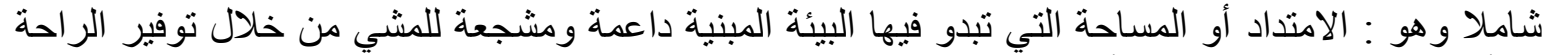

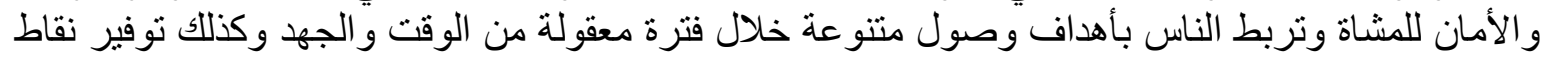

جذب بصرية خلال رحلته داخل هذه الثبكة. 
ترتبط معايير قابلية السير مباشرة بالعناصر المؤثرة في البيئة المبنية التي تزيد من التبر القدرة على المشي و وعناصر

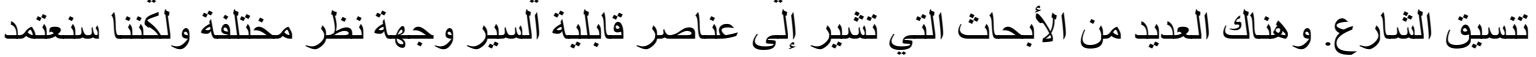

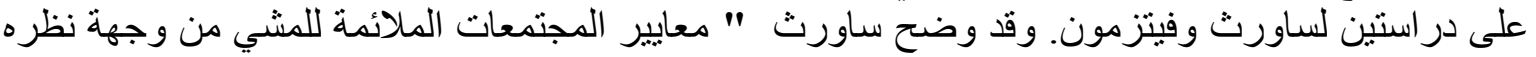

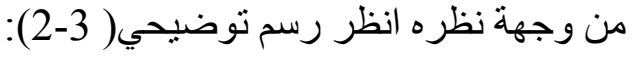

\section{معايير قابابية الفيبر}
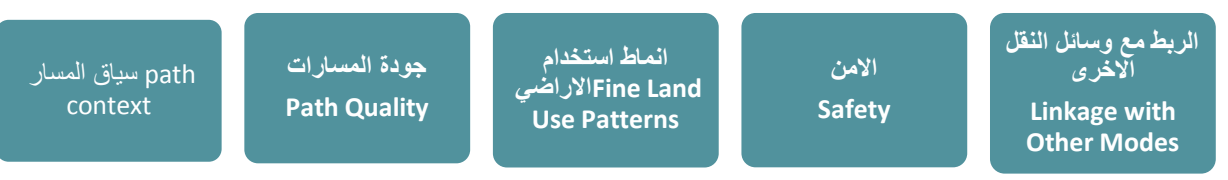

الاتصال

Connectivity

رسم توضيحي 9-معابير قابلبة السير الهصدر: الباحث عن Designing the walkable city

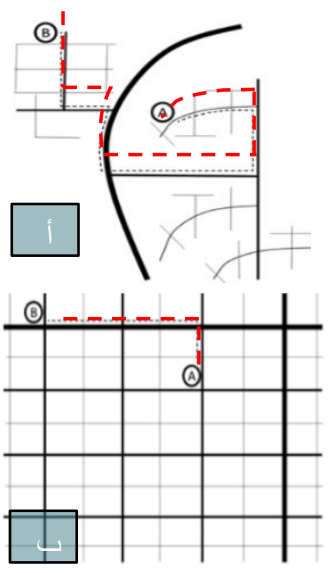

شكل 3 علاقة اتصال الشوارع بزيادة إمكانية المشي

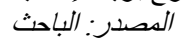

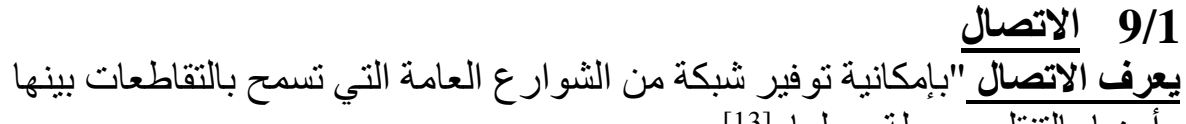

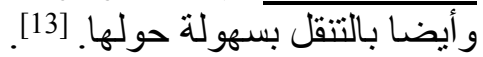

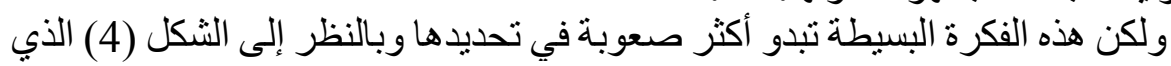

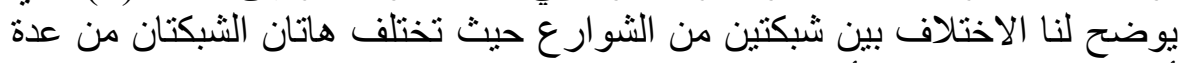

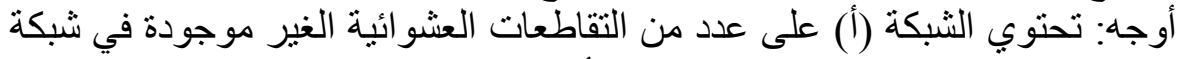

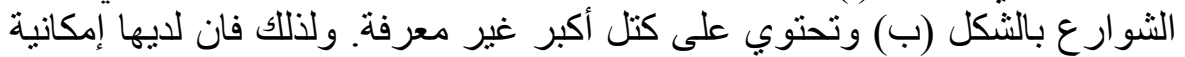

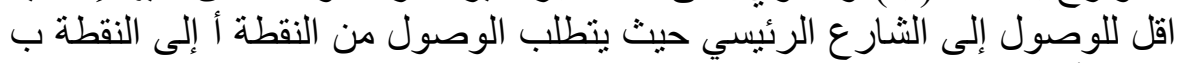

مسار أطول.

ويعرف اتصال مسارات المشاة بمدى تواجد أرصفة في الثوارع الثوار ومسار ات المشاة

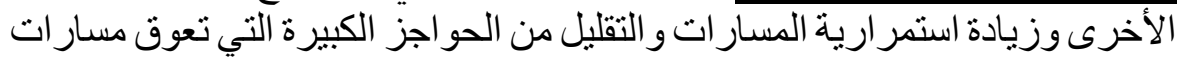

المشاة. [10]

\section{9/2}

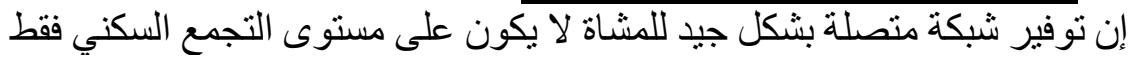

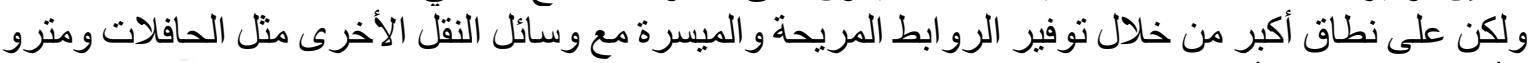

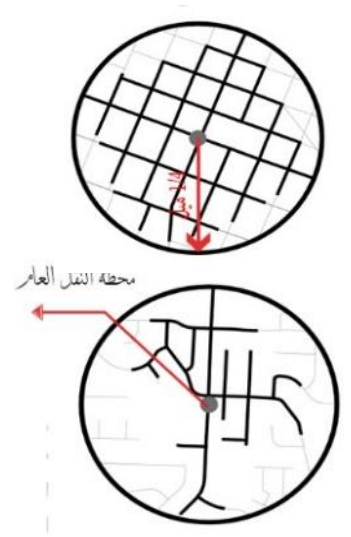

شكل 4الثكل اعلى بيوفر قابلية

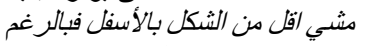
من وجود محطة النقل العام في دائرة نصف قطر ها ربع ميل المصدر:

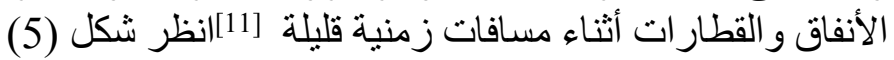

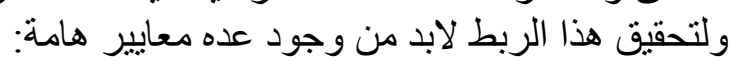

•وجود المحطات على مسافة كافية تسمح للمشاة بدخول المناطق السكنية

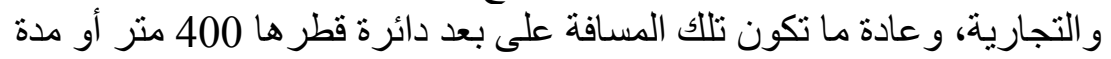
زمنية تقدر ب 5- 10 دفائق مثي.

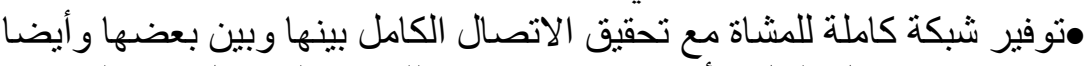
بينها و بين وسائل النقل الأخرى، بحيث بمكن للسكان الوصنئ الوصول بسهولة سيرا على الاقدام إلى المترو أو محطات الحافلات بدون أي حواجز اوتئن التقاطعات صعبة. •لابد من وجود شبكة نقل عام جيدة تضمن سهولة وصول المشاة إليها وتقع ضمن استخدامات الأر اضي المختلطة. 


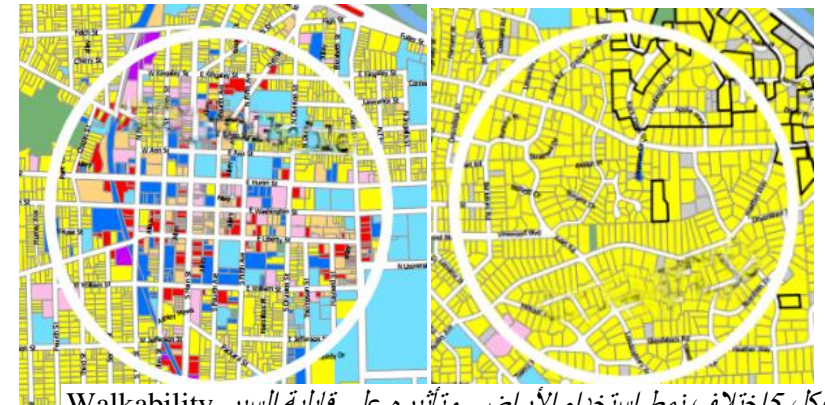

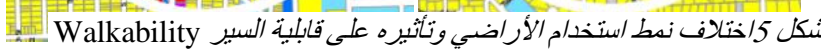
المصدر: الباحث عن: Smart Choices for developing our community: Idea Three

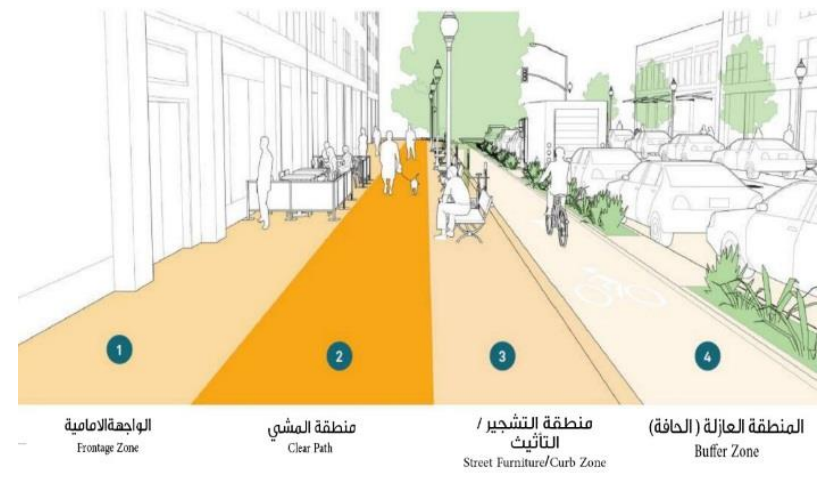

9/3 الاستخدامات المختلطة للأراضي:

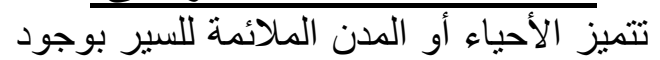

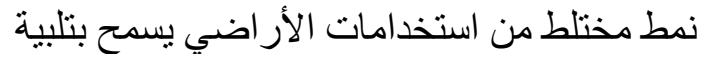

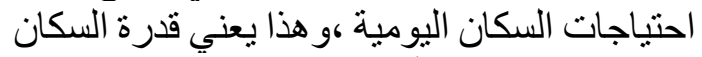

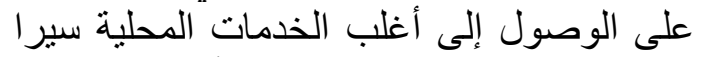

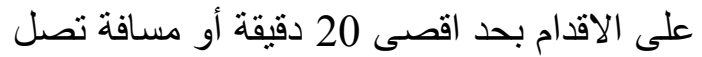

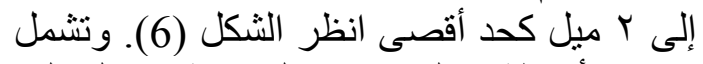

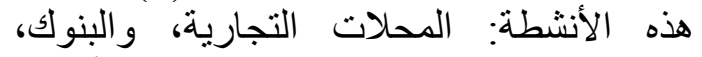
و المدارس الابتدائية، الحدائق و غير ها من الأنشطة

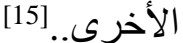

9/4

إن جودة مسار جودة المسيارات المشاة في حد ذاتها تشكل

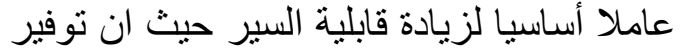
مساحات كافية لتلبية احتياجات المشادة المانة المعروفة

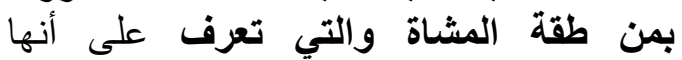
"المساحة بين حد الثار ع وخط ملكية العقار ات اتل

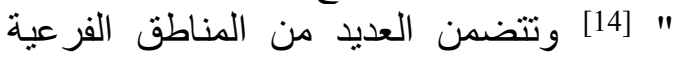

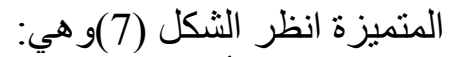
الواجهة الأمامية، منطقة الثية المشي الفئة الفعلية، منطقة التشجير/التأثيث، المنطقة العازلة النئ. 9/5 سياق المسار شكل 6 مكونات ننطقة المشاة الدصدر: الباحث عن Global Street

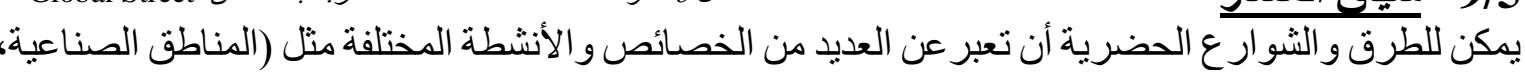

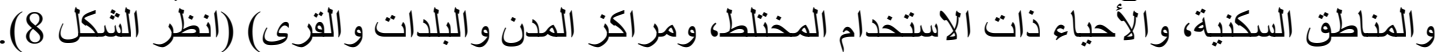

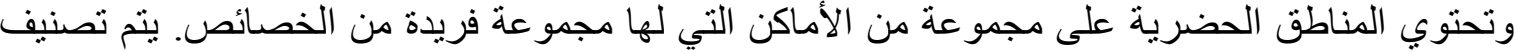

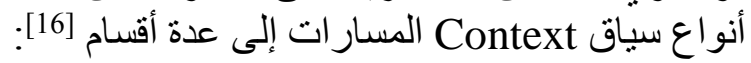

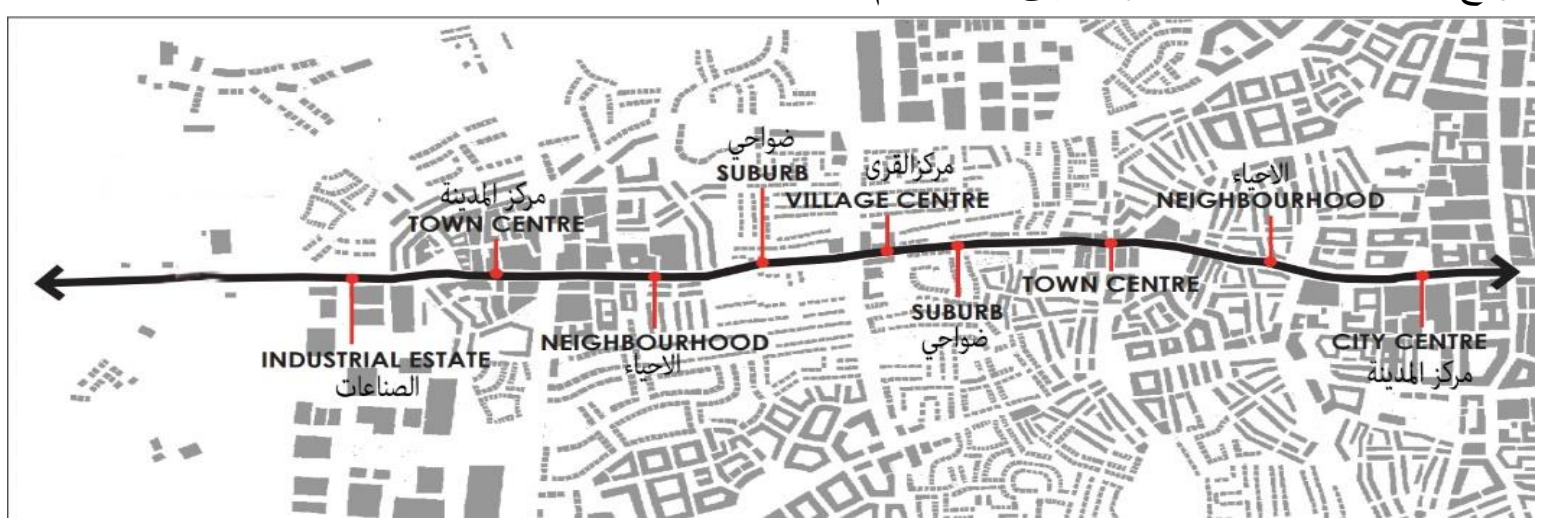

شكل 7 يمكن أن يمر الثارع أو الطريق عبر عدد من السياقات المختلفة على طول الطريق. وبذللك تختلف تصميم الثوارع و الطرق تلبعا لذلك

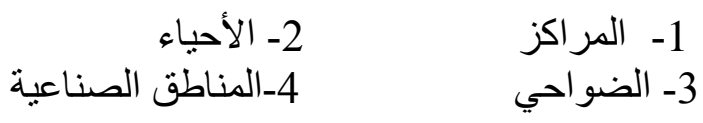


10/ الاراسة التحليلية : مشروع محور سان بابلو،كالفورنيا,(مريكا San Pablo,contra costa,California,America

10/1 موقع المشروع

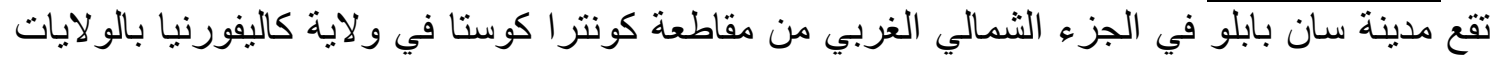

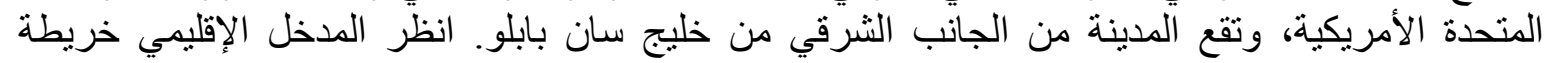
.$(1 \cdot 2 \cdot 3 \cdot 4)$

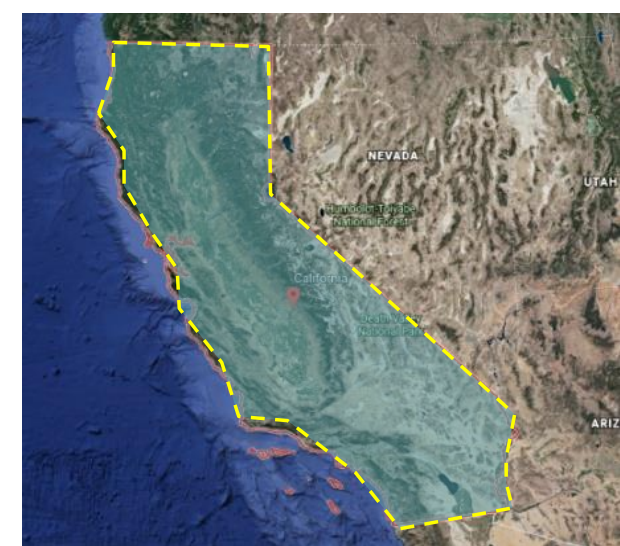

خريطة اولاية كاليفورنيا

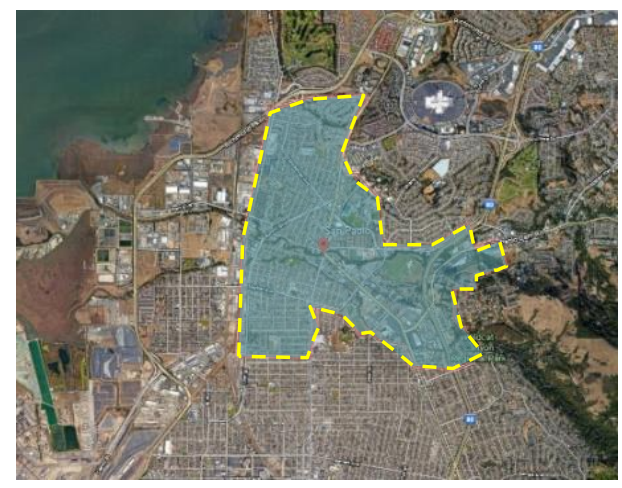

خربطة 3مدينة سان بابلو

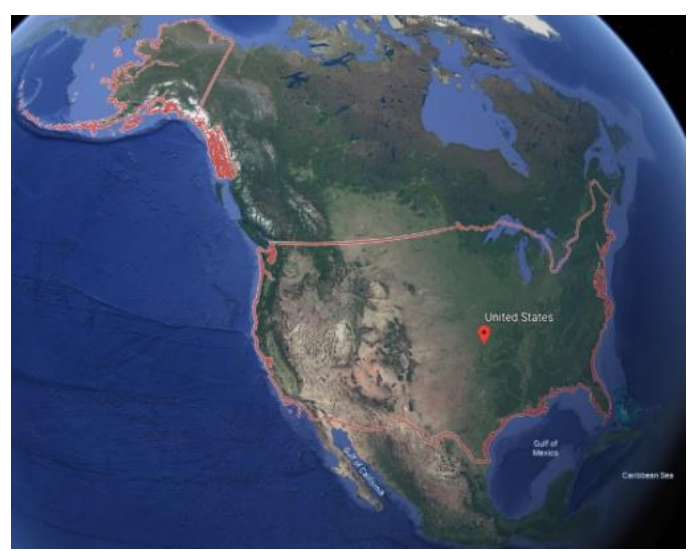

خربطة الولايات المتحدة الامريكبة

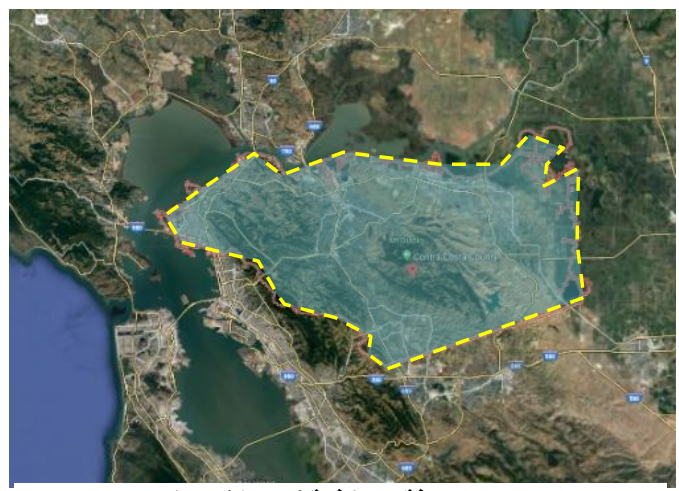

خر بيطة 4هقاطعة كو نتر / كو بتا

خريطة 5 الدذخل الاقلبيسي لمنطقة الدراسة بمحور سان بابلو، الولايات المتحدة الامريكبة المصدر:Google Earth

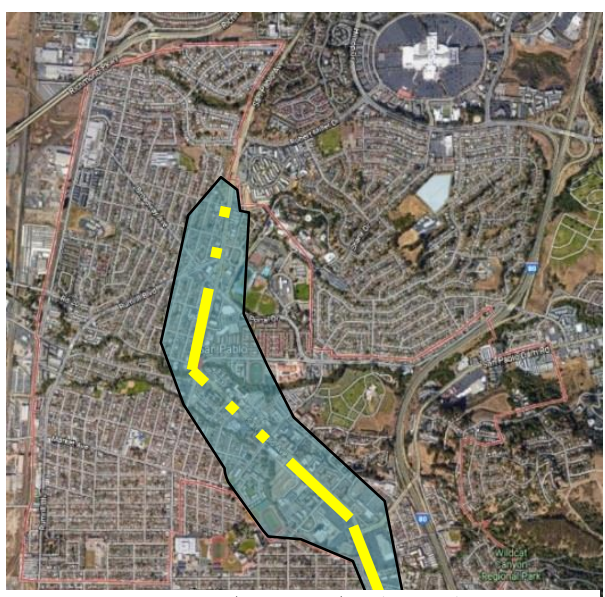

خريطة كمنطقة الدر/سة الدصدر: Google
10/2 منطقة الدراسة

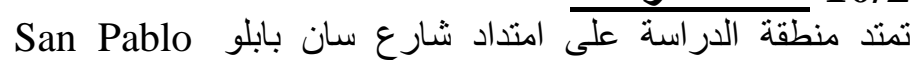

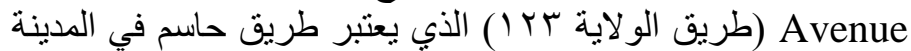
حيث يمر عبر أربع مدن وهي (أوكلاند، إيميريفيل، بيركليف حاني، ألباني) Oakland, Emeryville, Berkeley and Albany))

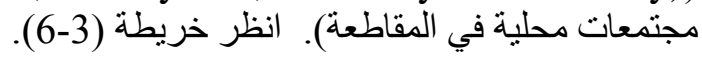

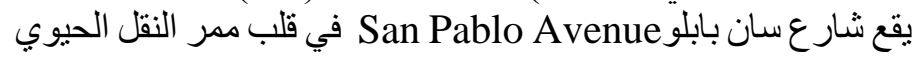

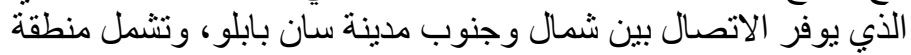

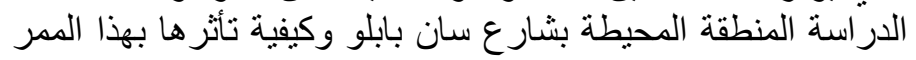

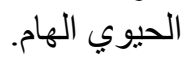
سنقوم في هذه الفقرة بدراسة وتحليل أنواع وسائل النقل المستدامة المنوفرة في مشرو عذه محور سان بابلو و أهمها: 
Noha Ahmed Nabil /Engineering Research Journal 166 (June 2020) AA104-AA116

10/3 تحليل معايير قابلية السير فى منطقة الدراسة 10/3/1 الاتصال 10/3

• تو افر مسار ات المشاة المتصلة بشكل جيد في منطقة الدراسة بمحور سان بابلو حيث تغيب الحو اجز التي تعثرض مسار ات المشاة.

ع يصل طول البلوك ما بين 150 و300 قدم مما يتيح قدرة كبيرة على الاتصال. كما هو موضح في شكل (9)

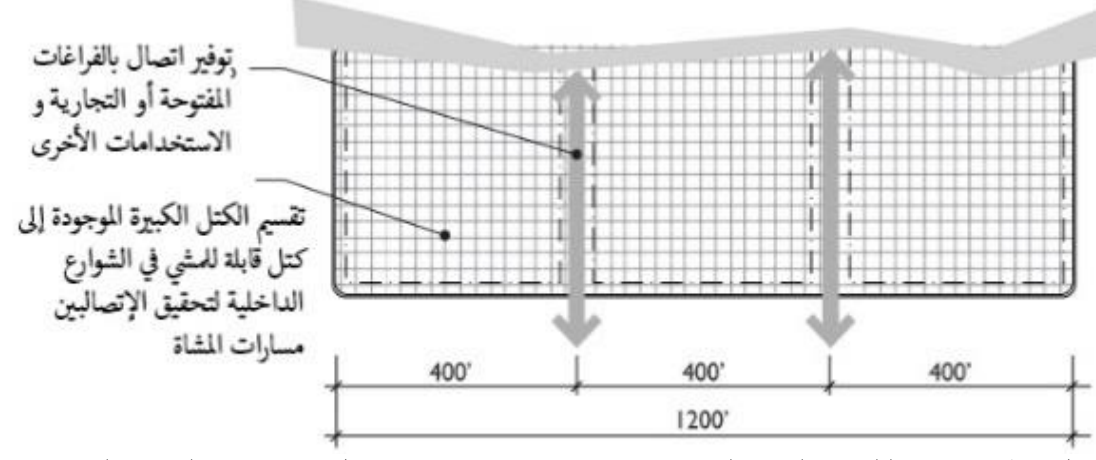

شكل 8 طريقة تقسبم البلوكات الكبيرة الى اخرى صغبرة تزبي من تحقبق الاتصال بين مسار ات المشاة المصدر:

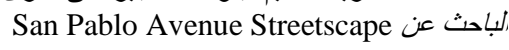

10/3/2 الربط مع وسائل النقل الأخرى

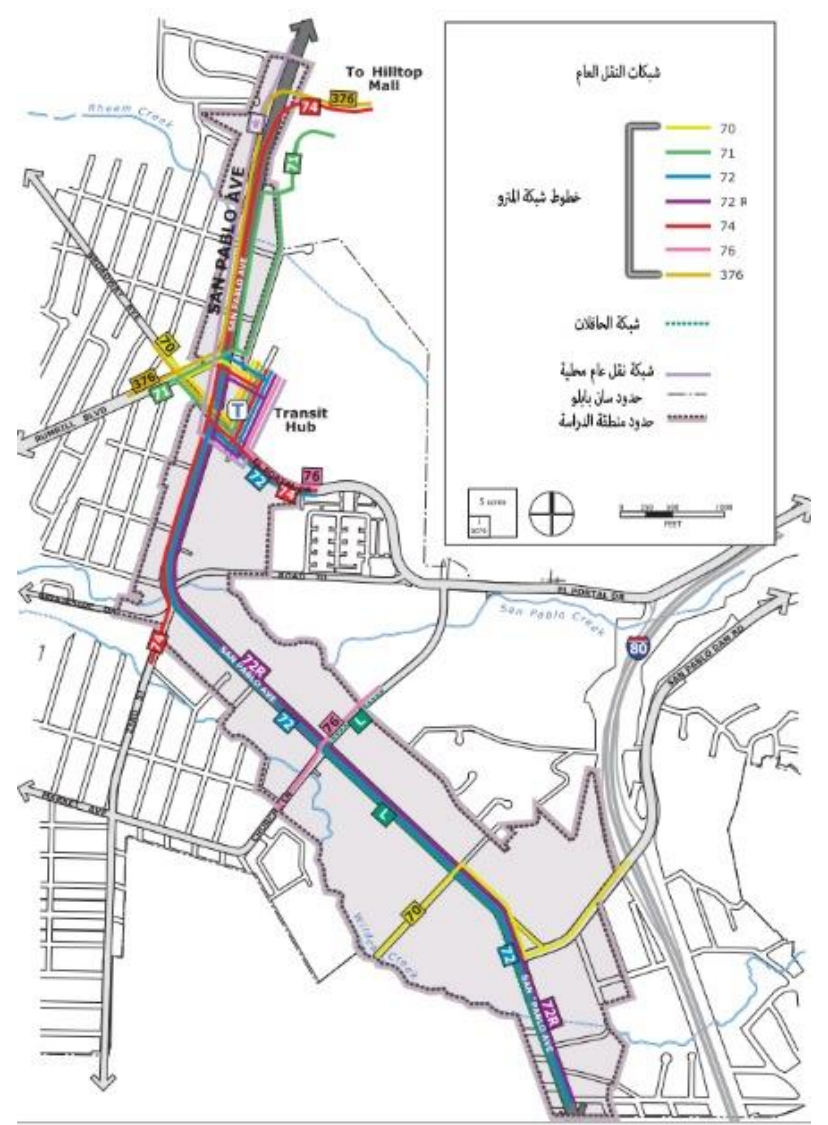
وختيح وجود وسائل النقل العام مثل المنرو مناسبة للمشي في منطقة الدر اسة.

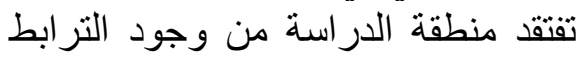

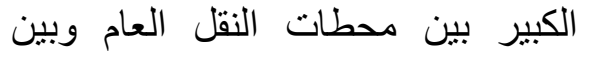
مسار ات المشاة انظر الخريطة (7).

خريطة 7شبكات النقل العام المصدر: San Pablo Avenue Streetscape 
• تم وضع علامات عبور للمشاة عند أماكن التقاطعات وذلك لزيادة الثعور بالأمان.

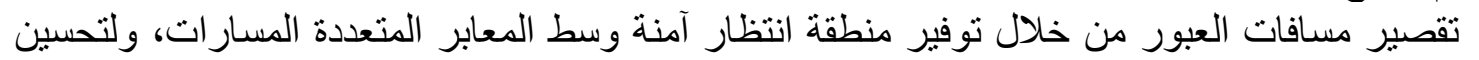

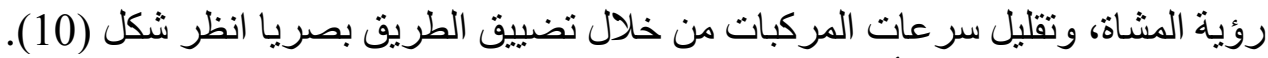

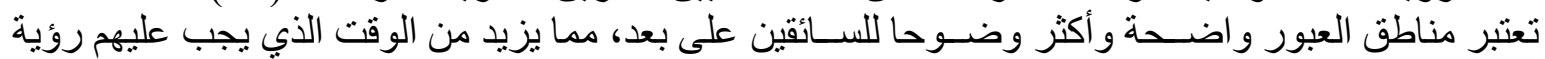

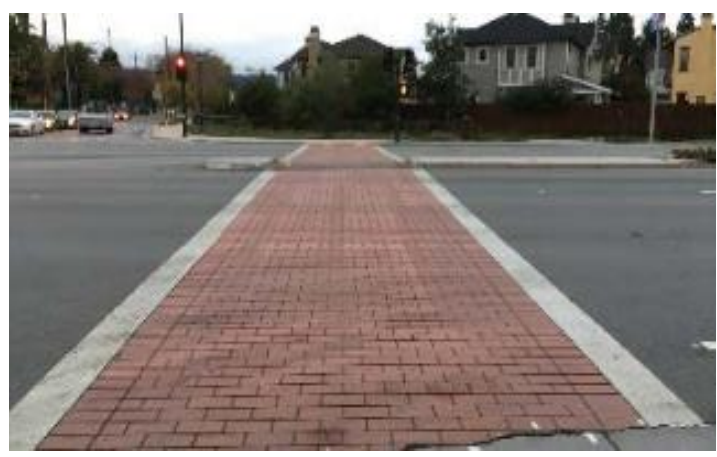

شكل ووضوح أماكن العبور للمشاة بقلل من خطر الحوادث الهصد:CITY of SAN PABLO Bicycle and

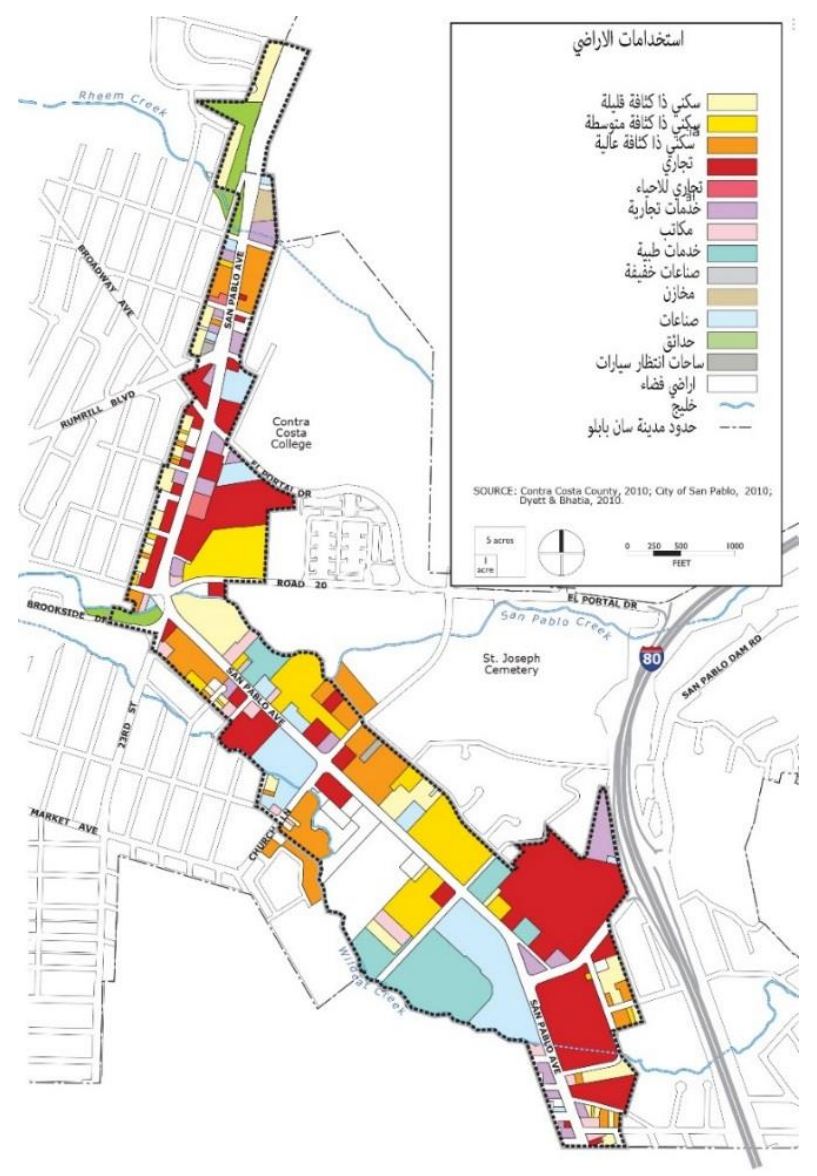

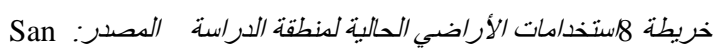
Pablo Avenue Streetscape Frontage, Baxter Creek
المشاة و التوقف عندهم. كما هو موضنح في شكل (11)

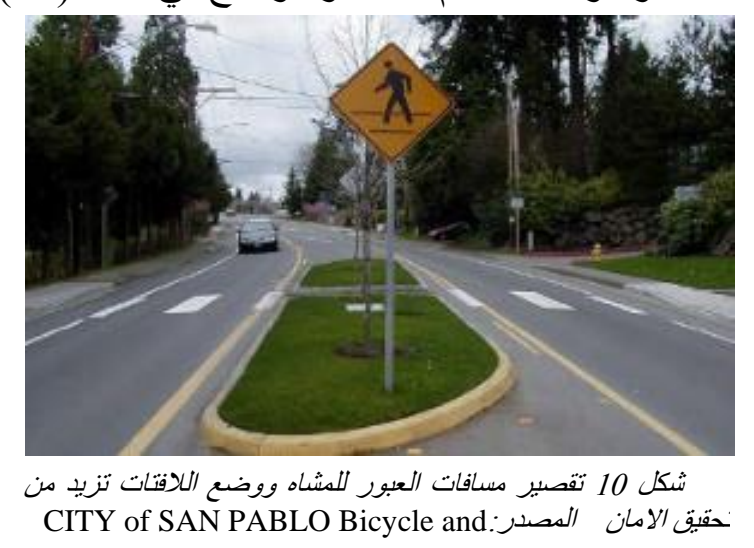

\section{0/3/4 الاستخدام المختلط للأر اضي}

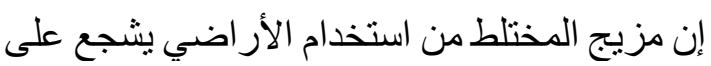
حركة المشاة ويجعل من المدر منطقة مشي حيوية مختلطة الاستخدام كما هو موضح في خريطة (8). انظر . الشكلين (12)و (13).

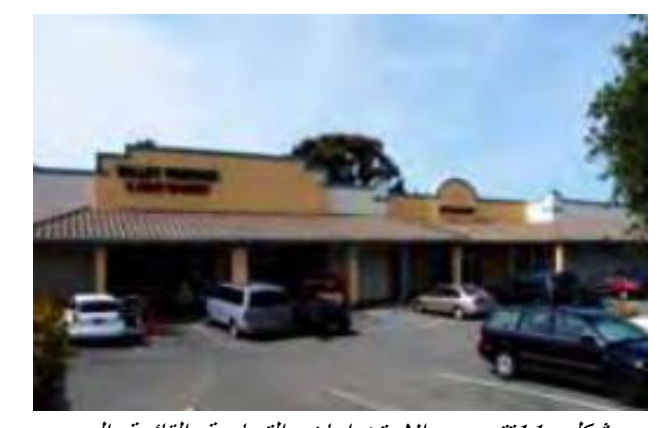

شكل 11تتضمن الاستخدامات التجارية القائدة العديد من التهن لمراكز التجارية القديمة الهصدر: San Pablo Avenue Streetscape Frontage, Baxter Creek

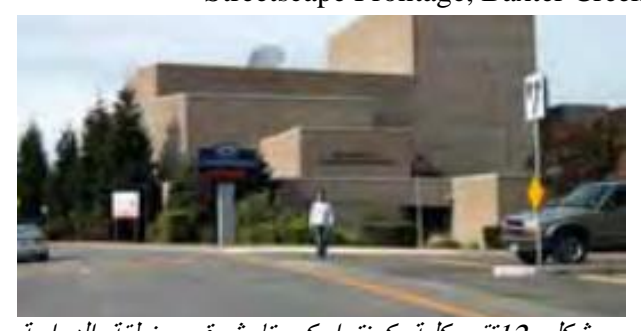

شكل 12تقع كلية كونتر/ كوستا شرقي منطقة الدراسة

San Pablo Avenue Streetscape Frontage, : لمصند Baxter Creek 
10/3/5

ان تو افر العناصر التجميلية بالثوارع، وعناصر التأثيث ومناطق التظليل، يمكن أن تجعل المشي مريحة أكثر وتعزز بيئة المشاة لجعل المشي أكثر جاذبية. انظر شكلين (14 و 15)

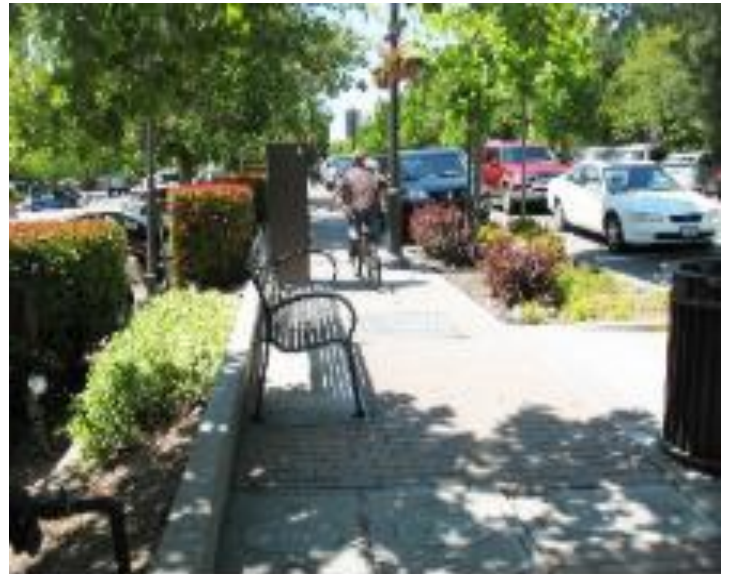

شكل 15 وجود عناصر الثأثيث والعناصر التجميلبية في الثوارع يزبيد

سن قابلبة السير في مدر سان بابلو الدصدر: San Pablo General Plan 2030

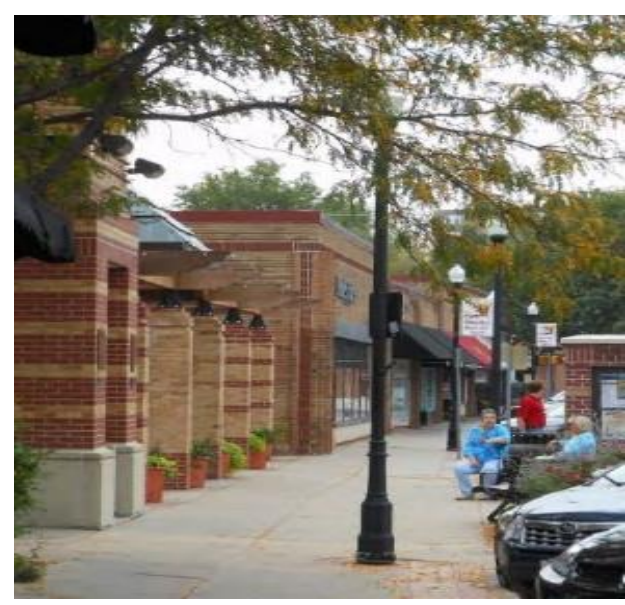

شكل 13 مثال بوضح أهبية التشجبير ووجود عناصر كأثثبث بأحد شوارع منظقة الدراسة/المصدر: Olsson Associates

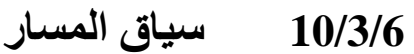

هعبر سياق المسار في منطقة الدر اسة عن سياق مر اكز المدن حيق يعتبر محو سان بابلو ذا أهمية كبيرة لما يتميز به من سياق مميز يسمح بقابلية السية السير.

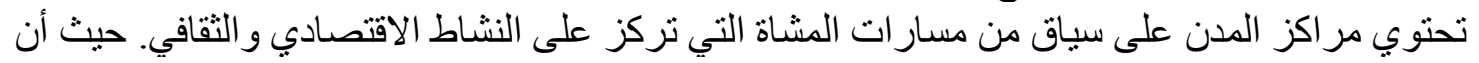
حركة المشاة تزيد في مراكز المدن حيث يتحرك معظم الناس إلى المراكز بوراسطة وسئل وسائل النقل Transportation

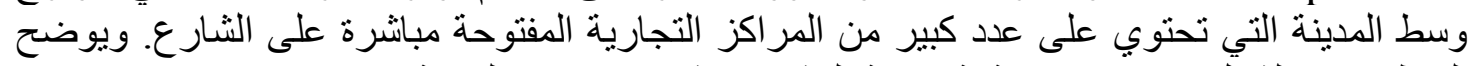

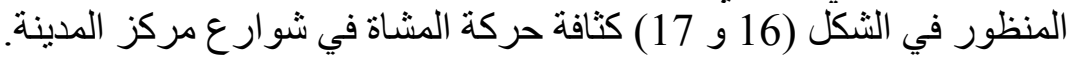

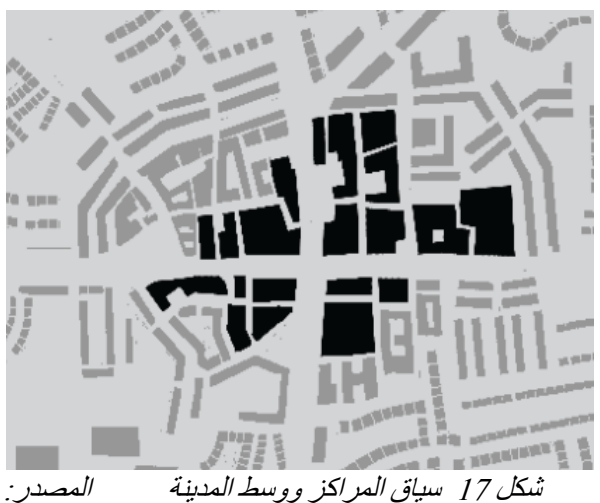

Design Manual for Urban Roads and Streets

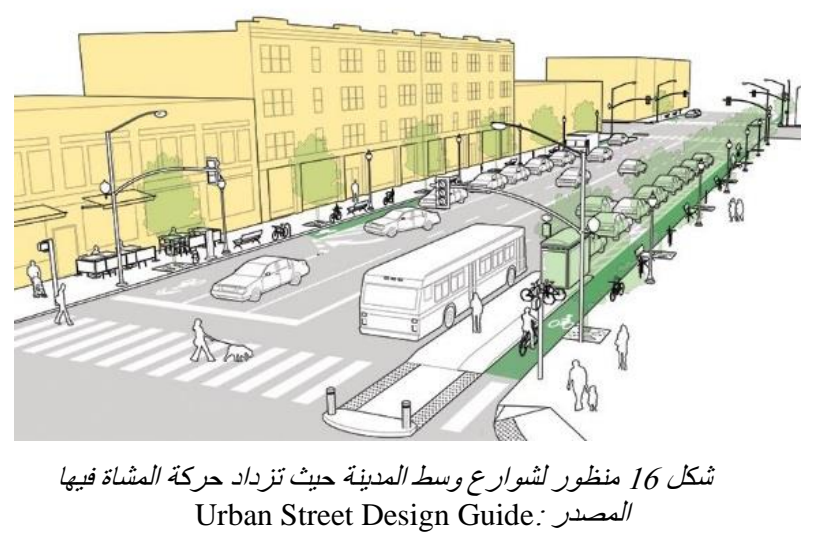


يهدف النقل المستدام الى توفير أسلوب نقل أكثر كفاءة واقل تكلفة، يحقق الاتصال والتكامل بين

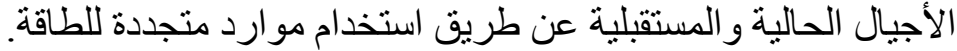
هدعو النقل المستدام الى تحقيق أهداف الاستدامة ومبادئها الثلاثة و هي المبادئ البيئية والاجتماعية و والاقتصادية. ليعتبر السير من أهم وسائل النقل المستدام، والتي تصنف حسب القوة المحركة ضمن وسائل النقل النشط ان التنوع في وسائل النقل العام وربطها بمسار ات المشاة يزيد من قابلية السير بحيث لا تزيد هذه

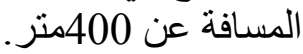
يعتبر الاتصال بين مسارات المشاة من أهم معايير قابلية السير، ويتحقق عن طريق التقليل من الحو اجز و العو ائق، وتقليل الثقاطعات المرورية. يعتبر عنصر الأمن من أهم عناصر قابلية السير و التي تقلل بشكل كبير من حوادث المرور المتعلقة

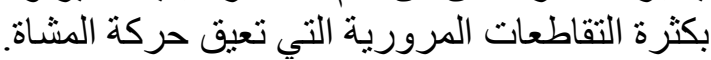

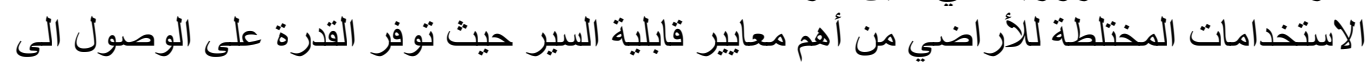
مختلف السلع والاحتياجات اليومية للسكان.

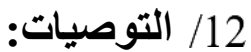

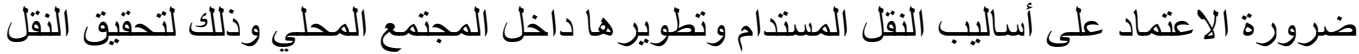

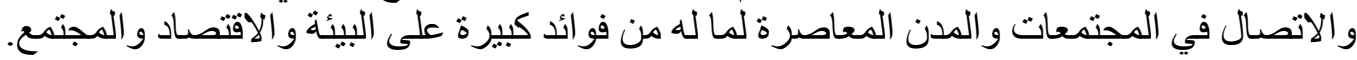

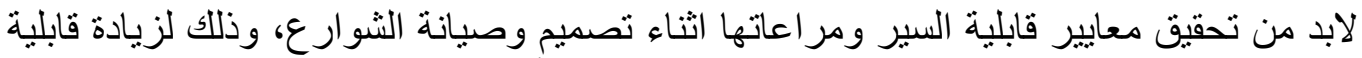
السير داخل المجتمعات العمر انية، وبالتالي تحقيق نظم نقل ألتائل أكثر استدامة.

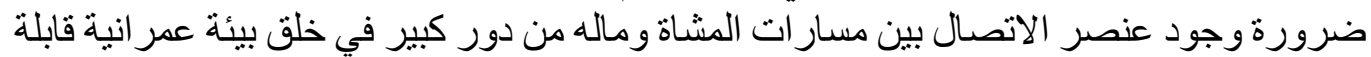

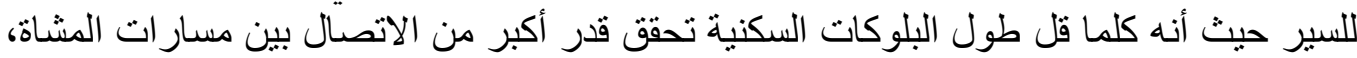

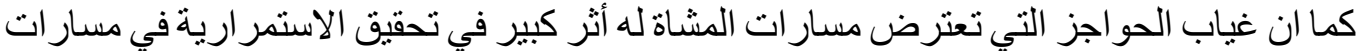
المشاة مما يزيد قابلية السير في منطقة البر فئر الدراسة. ضرورة توفير الترابط بين شبكات النقل المختلفة وبين مسار ات المشئة المشاة، وذلك لزيادة قابلية السير داخل المجتمعات العمر انية.

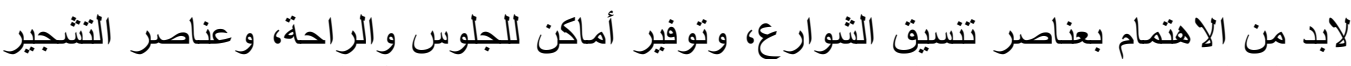

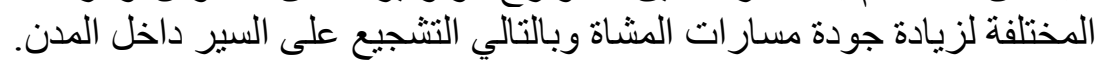

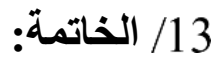

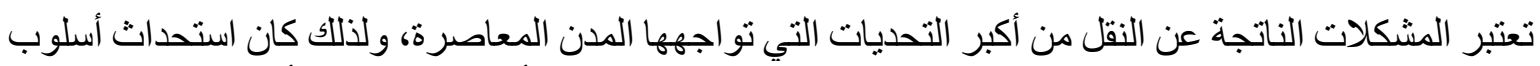

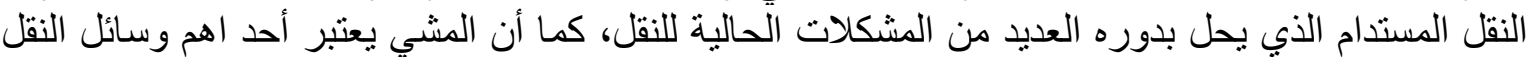

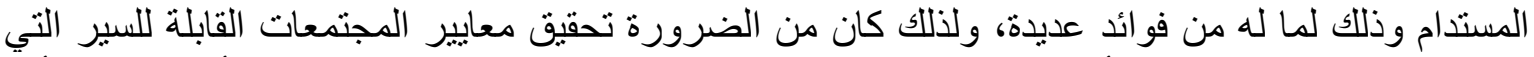

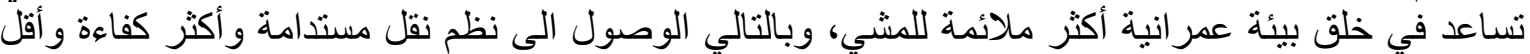




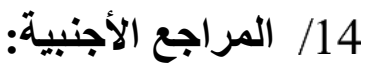

[1] M. H. . Zuidgeest, M. J. G. Witbreuk, and M. F. a. M. Van Maarseveen, "Sustainable Transport : a Review From a Pragmatic Perspective," 19th South. African Transp. Conf., no. July, pp. 17-20, 2000.

[2] E. Knaap, C. Ding, and Y. Niu, "Polycentrism as a Sustainable Development Strategy: Empirical Analysis from the State of Maryland Forthcoming in the Journal of Urbanism Polycentrism as a Sustainable Development Strategy: Empirical Analysis for the State of Maryland," pp. 1-33. 4-5تاريخ الاطلاع:2020

[3] H. Gudmundsson, R. P. Hall, G. Marsden, and J. Zietsman, Springer Texts in Business and Economics Sustainable Transportation. no.17 1-5-2020 تاريخ الاطلاع

[4] R. P. Hall, "Introducing the Concept of Sustainable Transportation to the U . S . DOT through the Reauthorization of TEA-21," 2002.

[5] T. Litman, "Active Transportation Policy Issues," Traffic Saf., 2003.

[6] R. Rafiemanzelat, M. I. Emadi, and A. J. Kamali, "City sustainability: the influence of walkability on built environments," Transp. Res. Procedia, vol. 24, pp. 97-104, 2017, doi: 10.1016/j.trpro.2017.05.074.

[7] B. Ryan, "Economic Benefits of A Walkable Community," Let's Talk Bus., no. 83, 2003, [Online]. Available: http://fyi.uwex.edu/downtowneconomics/files/2012/07/economic-benefits-ofa-walkable-community.pdf.

[8] M. H. Y. Hawar Taha Tawfeeq, Amjad M. Ali Qaradaghi, "The effect of Vehicle traffic on walkability at the old city of Sulaimaniyah," Sulaimani J. Eng. Sci., vol. 6, no. 1, pp. 45-63, 2019, doi: https://doi.org/10.17656/sjes.10076.

[9] Wasatch Front Regional Council et al., "Utah Street Connectivity Guide," no. March, 2017.

[10] M. Southworth, "Designing the walkable city," J. Urban Plan. Dev., vol. 131, no. 4, pp. 246257, 2005, doi: 10.1061/(ASCE)0733-9488(2005)131:4(246).

[11] J. Dill, "Measuring network connectivity for bicycling and walking," 83rd Annu. Meet. Transp. ..., no. 1, p. 20, 2004, [Online]. Available: http://reconnectingamerica.org/assets/Uploads/TRB2004001550.pdf.

[12] EDA Collaborative Inc., "SmartChoices for developing our community: Idea Three," pp. 5770,: https://webdocs.edmonton.ca/InfraPlan/SmartChoices/Catalogue/Idea3EDAWalkableCity.pdf.

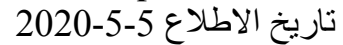

[13] H. O. W. M. Connectivity et al., "Street Connectivity.", Lehigh Valley Planning

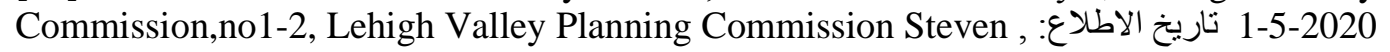

[14] A. Minneapolis, "Minneapolis Pedestrian Master Plan," 2009. , Minneapolis CITY COUNCIL,

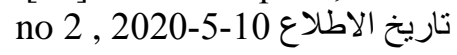

[15] T. H. E. City and O. F. San, "THE CITY OF SAN DIEGO Transportation \& Storm Water Design Manuals," vol. 1, no. July 2016, 2017.

[16] Department of Transport Tourism and Sport, "Design Manual for Urban Roads and Street," p. 165, 2013, [Online]. Available: http://www.environ.ie/en/Publications/DevelopmentandHousing/Planning/FileDownLoad,32669,en .pdf.

[17] Neun, M. and Haubold, H. 2016. The EU Cycling Economy - Arguments for an integrated EU تاريخ الاطلاع 1-5eling policy. European Cyclists' Federation, Brussels, December 2016 pp. 1-16.-1 ,2022

[18] B. C. Frontage, "San Pablo Avenue Streetscape," no. March, 2011.City of San Pablo,no15, 2020-5-10 تاريخ الاطلاع

[19] S. Pablo and A. Specific, "Neighborhood Streets. City of San Pablo,no22-20, - تاريخ الاطعلاع 2020-5 